\title{
Correlation of Random Urine Protein Creatinine (P-C) Ratio with 24-Hour Protein Urine in Lupus Nephritis Patients
}

\author{
YH Aini, ${ }^{1}$ A Tjandrawati, ${ }^{1}$ N Suraya, ${ }^{1}$ L Hamijoyo²
}

${ }^{1}$ Department of Clinical Pathology, Medical Faculty of Padjadjaran University, Hasan Sadikin Hospital, ${ }^{2}$ Department of Internal Medicine, Medical Faculty of Padjadjaran University, Hasan Sadikin Hospital Bandung, West Java, Indonesia

\begin{abstract}
Background : Systemic lupus erythematosus (SLE) is a systemic autoimmune disease involving multiple organs including kidney and known as lupus nephritis (LN). Lupus nephritis has a poor prognosis after a 10-years onset, more than $25 \%$ will be ended by end stage renal disease. There are glomerular and tubulointerstitial tissue damages due to immune complex deposits in LN which is activating inflamation cascade and causing disfunction of glomerular filtration and tubular reabsorption resulting proteinuria. In $\mathrm{LN}$, proteinuria is used to diagnose, to assess the disease activity and to monitor the therapy. The gold standard of proteinuria is 24-hour urine protein examination, but the process of collecting in 24 hour urine is difficult, then the result is less accurate and reliable. Another alternative parameter is spot urine protein/creatinine ratio. Several studies have found a positive correlation between spot urine protein/creatinine ratio and 24-hour urine protein levels, but in $\mathrm{LN}$, the results are various.
\end{abstract}

Objective. The aim of this study was analyzing the correlation between spot urine protein/creatinine ratio and 24-hour urine protein in lupus nephritis.

Methods. The study was conducted at Dr. Hasan Sadikin Hospital, Bandung, West Java, Indonesia in October 2014 to December 2014. The subjects were 45 patients with lupus nephritis based on the criteria of the American College of Rheumatology. The study analyzed correlation through cross-sectional model.

Results: The results of Spearman correlation test analysis showed a significantly strong positive correlation between spot urine protein/creatinine ratio and 24-hour urine protein levels in lupus nephritis ( $r s=$ $0.96 ; p<0.001)$. Based on the degree of proteinuria there was a strong positive correlation between spot urine protein/creatinine ratio and 24-hour urine protein levels in lupus nephritis significantly on the degree of protein $<1 \mathrm{~g} / 24-\mathrm{h}$ ( $\mathrm{rs}=0.91 ; \mathrm{p}<0.001)$ and at $1-3.5$ $g / 24-h(r s=0.73 ; p<0.05)$.

Conclusion : There is a significant strong positive correlation between spot urine protein/creatinine ratio and the 24-hour urine protein levels in lupus nephritis, so it is recommended to use spot urine protein/creatinine ratio, as an alternative quantitative examination in lupus nephritis.

Keywords: lupus nephritis, 24-hour urine protein, spot urine protein/creatinine ratio

\section{Background}

Systemic lupus erythematosus (SLE) is a systemic autoimmune disease involving multiple organs including kidney and known as lupus nephritis (LN). Lupus nephritis has a poor prognosis since after a 10 -years onset, more than $25 \%$ will be ended by end stage renal disease. There are glomerular and tubulointerstitial tissue damages due to immune complex deposits in $\mathrm{LN}$ which is activating inflamation cascade and causing disfunction of glomerular filtration and tubular reabsorption resulting proteinuria. ${ }^{1}$

In $\mathrm{LN}$, proteinuria is used to diagnose, to assess the disease activity and to monitor the therapy. The gold standard of proteinuria is 24-hour urine protein examination due to the variation of protein excretion, but the process of collecting in 24 hour urine is difficult, such as patients adherence, an adequate collection and handling of this material in the laboratory. Because of those difficulties, the results sometimes are less accurate and reliable. ${ }^{2}$

Another alternative parameter is spot urine protein/creatinine (P-C) ratio. Random urine protein/creatinine ratio is the measurement in an untimed spot urine specimen, which avoids the influence due to variations of urinary solute concentration and provides a more convenient method to assess protein excretion. This method is also recommended by National Kidney Foundation and Kidney Disease Outcomes Global Improving (KDIGO) clinical guidelines for glomerulonephritis ${ }^{3}$.

Several studies have found a positive correlation between spot urine protein/creatinine ratio and 24-hour urine protein levels in pregnant woman, chronic kidney disease, kidneytransplantation and as well as in children but in $\mathrm{LN}$, the results are various. Leung et al (2007) reported a good correlation and limits of agreement between the spot urine P-C ratio and 24 hour total protein levels across a wide range of proteinuria and recommended using the spot urine $\mathrm{P}-\mathrm{C}$ ratio in screening and monitoring significant proteinuria in patients with LN. In opposition to this statement, Birmingham et al $(2007)^{5}$ and Marques et al (2013) concluded that the random spot urine $\mathrm{P}-\mathrm{C}$ ratio is unreliable in monitoring proteinuria changes in individual $\mathrm{LN}$ patients an is also unreliable as a screening test. They found that this method 
underestimates and overestimates the results with about equal frequency. The aim of this study was analyzing the correlation between spot urine $\mathrm{P}-\mathrm{C}$ ratio and 24-hour urine protein level in lupus nephritis.

\section{METHODS}

\section{Study design}

We conducted a cross-sectional study of urine excretion at Dr. Hasan Sadikin Hospital from October 2014 to December 2014. The study analyzed correlation through cross-sectional model.

\section{Subjects}

Based on sample calculation, the minimal sample was 37 subjects. This study found 45 patients for subjects with lupus nephritis based on the criteria of the American College of Rheumatology. They all had clinical and laboratory diagnosis history of lupus nephritis. Menstruation, others glomerulopathy, urinary tract infection, spot urine collecting over 2 hours and inadequate 24-hour urine were excluded. All participants gave consent to be enrolled in this study and the study protocol had been approved by the Ethic Committee and Health Research of Hasan Sadikin Hospital Bandung Indonesia.

\section{Assessment}

All subjects submitted 24-hour urine collections and random spot urine specimens. To determine the accuracy of the 24-h collections, the following formula was calculated (prediction creatinine content-measured creatinine content)/ prediction creatinine content. The results $>0.2$ was deemed an under collection of 24-h urine or inadequate 24-h urine. Prediction creatinine content was measured by formula: 28 (0.2xAge) x Kg body weight for male and 23.8-(0.17xAge) $\mathrm{x}$ Kg body weight for female. The P-C ratio was calculated, dividing the urinary proteinuria by creatinine. Urine protein and creatinine measurements were conducted in Clinical Pathology laboratory of Hasan Sadikin Hospital Bandung using automated analyzer (Cobas Integra). Total protein was measured using turbidimetry (pyrogallol red) method and creatinine using enzymatic colorimetric method.

\section{Statistical analysis}

Statistical analysis was performed by SPSS 18.0 Statistical Analysis (SPSS Inc. Chicago, IL, USA). In the univariate analyses which are the characteristics of the subjects' data were presented by mean, median, standard deviation, minimum and maximum. In the bivariate analysis which is determined the strength of the correlation was calculating by Spearman correlation coefficient (data were not in normal distribution). Two sided $p<0.05$ was considered as statistically significant.

\section{Results}

A total 60 of 24-h urine samples were collected, with 15 samples were excluded for assessment because of inadequate 24-h urine collection. The remaining samples which could be assessed were 45 samples. The spot urine from 45 subjects assessed for urinalysis and random urine protein creatinine ratio.

The baseline characteristics of lupus nephritis subjects are presented in Table 1.

Table 1 Characteristics of lupus nephritis subjects

\begin{tabular}{lll}
\hline Variable & $\%(\mathbf{n = 4 5})$ & Mean $(\mathbf{S D})$ \\
\hline Age & & $32.23(10.91)$ \\
Sex & & \\
$\bullet \quad$ Female & 97.79 & \\
Onset of SLE & & \\
$\bullet<1$ year & 22.23 & \\
$\bullet \geq 1-5$ years & 33.27 & \\
$\bullet \geq 5-10$ years & 36.61 & \\
$\bullet \geq 10$ years & 8.89 & \\
Medication treatment & 100.00 & \\
\hline
\end{tabular}

The majority of subjects were female with mean age was about 32 years old. Early onset of glomerulonephritis in SLE was explained in onset of SLE less than 1 year $(22.23 \%)$. All subjects already had medication treatment for lupus nephritis. The clinical and laboratory characteristics of lupus nephritis patients at the time urine was collected are described in Table 2:

Table 2 Clinical and laboratory characteristics of lupus nephritis subjects

\begin{tabular}{lccc}
\hline Variable & $\mathbf{n}(\%)$ & Median & Min-Max \\
\hline Clinical features & $6(13.33)$ & & \\
Malaise & $3(6.67)$ & & \\
Fever & $3(6.67)$ & & \\
Athralgia & $4(8.89)$ & & \\
Malar Rash & $4(8.89)$ & & \\
Lupus hair & $1(2.22)$ & & \\
Photosensitive & $4(8.89)$ & & \\
Peripheral edema & $21(46.67)$ & & \\
Hypertension & & & \\
& & & \\
Laboratory features & $39(86.67)$ & & \\
Proteinuria & & 387.50 & $52.90-5800$ \\
Protein 24-h urine (mg/dL) & & 0.44 & $0.05-13.21$ \\
Random P-C ratio & $17(37.78)$ & & \\
Granular Cast & $9(20.00)$ & & \\
Microscopic hematuria & & 0.72 & $0.29-4.69$ \\
Serum creatinine levels (mg/dl) & & & \\
Estimated Glomerulus & & & \\
Filtration Rate/eGFR(mL/min) & & & \\
$\quad<60$ mL/min & $7(15.56)$ & & \\
\hline & & & \\
\hline
\end{tabular}

Lupus nephritis subjects had non-specific symptoms which were malaise, fever, arthralgia, rash, lupus hair and photosensitive and specific symptoms for renal involved which were peripheral edema and hypertension. Laboratory features showed proteinuria was the majority followed by granular cast and microscopic hematuria.

Statistical analysis of correlation between random urine $\mathrm{P}-\mathrm{C}$ ratio and $24-\mathrm{h}$ protein urine in lupus nephritis is 
represented by Spearman's (bivariate correlation) analysis between random urine $\mathrm{P}-\mathrm{C}$ ratio and $24-\mathrm{h}$ protein urine showed in Figure 1:

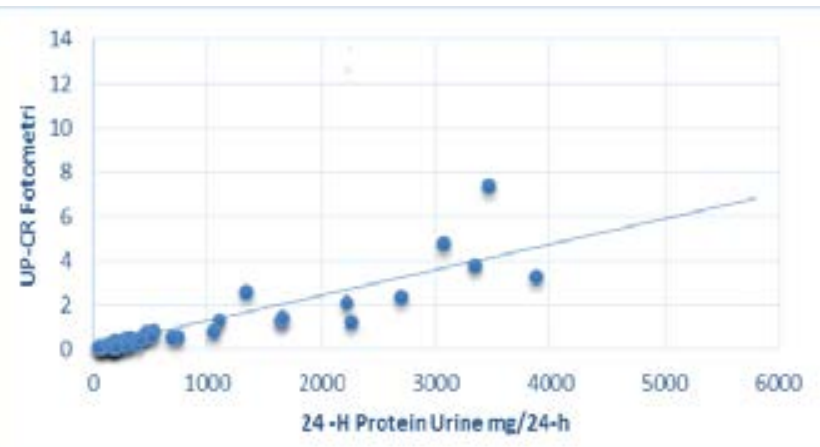

Figure 1 The correlation between amounts of random urine protein creatinine ratio and 24 -h protein urine collections

Correlation between random urine $\mathrm{P}-\mathrm{C}$ ratio and 24-h protein urine in a wide range showed an excellent positive correlation ( $\mathrm{rs}=0.96 ; \mathrm{p}<0.001)$ in Figure 1 .

Statistical analysis of correlation between random urine $\mathrm{P}-\mathrm{C}$ ratio and 24-h protein urine in lupus nephritis sorted by class of proteinuria are represented in Table 3:

Table 3 Statistical analysis of correlation between random urine p-c ratio and 24-h protein urine in lupus nephritis sorted by class of proteinuria

\begin{tabular}{|c|c|c|c|c|c|}
\hline \multirow[b]{2}{*}{$\begin{array}{l}\text { Class of } \\
\text { Proteinuria }\end{array}$} & \multirow[b]{2}{*}{ n } & \multicolumn{2}{|c|}{$\begin{array}{l}\text { Random Urine } \\
\text { P-C ratio }\end{array}$} & \multirow[b]{2}{*}{$r_{s}$} & \multirow[b]{2}{*}{ P Value*) } \\
\hline & & $\begin{array}{l}\text { Median } \\
(\mathrm{mg} / \mathrm{dl})^{*}\end{array}$ & $\begin{array}{c}\text { Min- } \\
\text { Max } \\
\text { (mg/dl) }\end{array}$ & & \\
\hline $\begin{array}{l}\text { Minimal Pro- } \\
\text { teinuria } \\
(<1 \mathrm{~g} / 24-\mathrm{h})\end{array}$ & $31(68.89)$ & 0.20 & $0.05-0.78$ & 0.91 & $<0.001$ \\
\hline $\begin{array}{c}\text { Moderate Pro- } \\
\text { teinuria (1-3.5 } \\
\text { g/24-h) }\end{array}$ & $12(26.67)$ & 2.16 & $0.74-3.74$ & 0.73 & 0.007 \\
\hline $\begin{array}{l}\text { Severe Protein- } \\
\text { uria } \\
\text { (>3.5 g/24-h) }\end{array}$ & $2(4.44)$ & 5.80 & $3.23-3.29$ & - & - \\
\hline
\end{tabular}

${ }^{*}$ Kruskall Wallis Test, $r$ s = Spearman's correlation coefficient, $\mathrm{p}$ Value significant if $p \leq 0.05$

Based on the degree of proteinuria there was an excellent positive correlation between spot urine protein/creatinine ratio and 24-hour urine protein levels in lupus nephritis significantly on minimal protein or $<1 \mathrm{~g} / 24 \mathrm{~h}(\mathrm{rs}=0.91 ; \mathrm{p}$ $<0.001$ ) and a strong positive correlation between spot urine protein/creatinine ratio and 24-hour urine protein levels in lupus nephritis significantly on moderate protein or $1-3.5 \mathrm{~g} /$ $24 \mathrm{~h}(\mathrm{rs}=0.73 ; \mathrm{p}<0.05)$.

\section{Discussion}

This study result shows a positive correlation between random urine protein/creatinine ratio and 24-hour protein urine in patients with lupus nephritis were significantly $(p<0.001)$ with the strength of correlation of 0.96 (excellent correlation). The result is consistent with the previous researches of random urine P-C ratio in lupus nephritis subjects. Nagasako et al. ${ }^{7}$ in 2007 said that the results of the correlation between urine protein/creatinine ratio and 24-hour protein urine of each study would vary depending on the subject's disease, the target population and collecting time of the urine specimens. The results of researches showed a great positive correlation between urine P-C ratio and 24-hour protein urine levels in patients with lupus nephritis from different countries can represent various ethnic populations, so we can conclude that there were no differences in the results of the correlation between spot urine P-C ratio and 24-hour protein urine levels in patients with lupus nephritis by ethnicity/race. The collecting times specimens for spot urine P-C ratio either first morning urine or random urine as well give equally good results in studies of the correlation between spot urine P-C ratio and the 24-hour protein urine levels in patients with

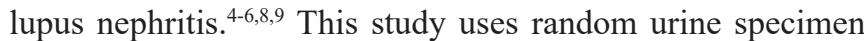
(untimed collection), because specimen is most commonly performed examinations, easy and convenient for the patient. This urine specimen can be collected at any time without the need for patient preparation prior research. Xin et al. ${ }^{10}$ in 2004 and Datta et al. ${ }^{11}$ in 2013 mentioned the correlation between spot urine $\mathrm{P}-\mathrm{C}$ ratio from first morning urine or random urine with 24-hour protein urine respectively each gave the same result, which was a strong positive correlation.

Previous research on random urine $\mathrm{P}-\mathrm{C}$ ratio and 24hour protein urine based on degree of proteinuria, gave different results. Birmingham et al. ${ }^{5}$ in 2007 had a weak agreement in proteinuria levels of 1 to $3.5 \mathrm{~g} / 24-\mathrm{h}$ and said that random urine protein/creatinine ratio could be used only in the minimal proteinuria level but could not be used in moderate proteinuria levels or flares. Marques et al. ${ }^{6}$ in 2013 had a weak correlation in proteinuria levels of $<500 \mathrm{mg} / 24-\mathrm{h}$ and there was no correlation in the range proteinuria of $<1$ g/24-h. Birmingham et al. and Marques et al. showed urine $\mathrm{P}-\mathrm{C}$ ratio had underestimated or overestimated results for 24-hour protein urine levels. They concluded that the 24-hour protein urine assessment still have to be maintained to assess proteinuria in lupus nephritis., 5

This study provides different result against Marques et al. and Birmingham et al. The results of this study show an excellent positive correlation between urine $\mathrm{P}-\mathrm{C}$ ratio and 24-hour protein urine either in groups of in minimal proteinuria $(<1 \mathrm{~g} / 24-\mathrm{h})$, and a good correlation in the moderate proteinuria group ( 1 to $3.5 \mathrm{~g} / 24-\mathrm{h}$ ) significantly. The results of this study reinforces the notion that the daily variation of the protein depends on the hydration status of individuals and then corrected by constant creatinine excretion will eliminate spurious results urine protein excretion rate and has an estimated rate approaching the estimated 24-hour total protein urine.

This research obtained the difference in the strength of the urine $\mathrm{P}-\mathrm{C}$ ratio and 24-hour protein urine levels between groups of minimal proteinuria $(<1 \mathrm{~g} / 24-\mathrm{h})$ compared to 
moderate proteinuria group ( 1 to $3.5 \mathrm{~g} / 24-\mathrm{h}$ ). The strength of the correlation urine $\mathrm{P}-\mathrm{C}$ ratio and 24-hour protein urine levels has decreased trend while the degree of proteinuria is more severe.

The reason alleged is due to the characteristics of proteinuria in lupus nephritis is different than proteinuria in chronic kidney disease non-SLE. Birmingham et al. ${ }^{12}$ in 2008 mentioned that proteinuria in lupus nephritis was the type of hypoalbuminuria. Lupus nephritis is a disease with an inflammatory process as to found an increase in the albumin catabolism, resulting in decreased albumin in the blood and urine excretion. The situation is more severe as active lupus nephritis increases. Type of proteinuria in lupus nephritis is dominated by non-selective high molecular weight protein excretion. Assessment of proteinuria in lupus nephritis using urine reagent test pyrogallol red is more difficult to detect the type of proteins other than albumin, so the results could be underestimated.

Another reason is suspected because the majority subjects in lupus nephritis are female who have a smaller muscle mass. The production creatinine could be less, so the lower urinary creatinine excretion causes overestimated urine $\mathrm{P}-\mathrm{C}$ ratio results.

The difference in results rs (strength of correlation) between groups could also be caused by the possibility of bias which were differences the number of $\mathrm{n}$ between the 2 groups. Moderate proteinuria group which has less number of $\mathrm{n}(\mathrm{n}=$ 12 ), so using a power test of $80 \%$, would be obtained rs is becoming smaller. It is possible if the number $n$ in the 2 group of proteinuria are balanced then the value obtained rs might be greater in moderate proteinuria group. Correlation value in the group of severe proteinuria $(>3.5 \mathrm{~g} / 24-\mathrm{h})$ is not obtained because the number of $n$ is too small $(n=2)$. Based on the subject that urine protein $5800 \mathrm{mg} / 24-\mathrm{h}$ has a value urine P-C ratio as 3.23 and subject that urine protein $3877.1 \mathrm{mg} / 24-\mathrm{h}$ has a value urine $\mathrm{P}-\mathrm{C}$ ratio as 3.29 , but these are not yet drawn any conclusions about the correlation.

This study could not establish a regression equation for random urine P-C ratio because the data is not normally distributed. Previous studies obtained equivalent value of random urine $\mathrm{P}-\mathrm{C}$ ratio and 24-hour protein urine levels in the values of $0.5 ; 1$, and $3.5 \mathrm{~g} / 24$ hours. Leung et al. ${ }^{4}$ mentioned that the value of random urine $\mathrm{P}-\mathrm{C}$ ratio as 0.45 ; 0.7 and $1.84 \mathrm{mg} / \mathrm{mg}$ were equivalent to 24-hour protein urine values of $0.5 ; 1.0$ and $3.5 \mathrm{~g} / 24$ hours. Ginsberg et al. ${ }^{13}$ in 1983 mentioned the values of random urine P-C ratio as 0.2 and 3.5 represent the value of abnormal urine protein and urine protein nephrotic value.

Limitation of this study is the number $\mathrm{n}$ in the group of subjects based on the degree of proteinuria are not balanced, especially for subjects with severe proteinuria (nephrotic), so in this range could not be assessed the correlation of random urine P-C ratio. All subjects in the study had been getting treatment, so that the study could not able to assess the correlation between random urine $\mathrm{P}-\mathrm{C}$ ratio and 24 hours protein urine on before treatment condition.

\section{Conclusion}

There is a significant excellent positive correlation between random urine protein/creatinine ratio and the 24-hour urine protein levels in lupus nephritis, so it is recommended to use random urine protein/creatinine ratio, as an alternative quantitative examination in lupus nephritis.

\section{References}

1. de Zubiria Salgado A, Herrera-Diaz C. Lupus nephritis: an overview of recent findings. Autoimmune Dis. 2012;2012:849684.

2. Solorzano GT, Silva MV, Moreira SR, Nishida SK, Kirsztajn GM. Urinary protein/creatinine ratio versus 24-hour proteinuria in the evaluation of lupus nephritis. J Bras Nefrol. 2012;34(1):64-7.

3. Kidney Disease Outcomes Quality Initiative (K/DOOI) Guidelines: Clinical Practice Guidelines for Chronic Kidney Disease: Evaluation, Classification and Stratification. Guideline 5 Assesment of Proteinuria. New York: National Kidney Foundation, Inc.; 2002. p. 100-12.

4. Leung YY, Szeto CC, Tam LS, Lam CW, Li EK, Wong KC, et al. Urine proteinto-creatinine ratio in an untimed urine collection is a reliable measure of proteinuria in lupus nephritis. Rheumatology (0xford). 2007;46(4):64952.

5. Birmingham DJ, Rovin BH, Shidham G, Nagaraja HN, Zou X, Bissell M, et al. Spot urine protein/creatinine ratios are unreliable estimates of 24 $\mathrm{h}$ proteinuria in most systemic lupus erythematosus nephritis flares. Kidney Int. 2007 0ct; 72(7):865-70.

6. Marques MG, Cotavia P, Ferrer P, Silva C, Botelho C, Lopes K, et al. Random spot urin protein/creatinine ratio: a reliable method for monitoring lupus nehritis. Clin Kidney J. 2013;6:590-4.

7. Nagasako H, Kiyoshi Y, Ohkawa T, Kaku Y, Koriyama C, Hamada K, et al. Estimation of 24-hour urine protein quantity by the morning-urine protein/ creatinine ratio. Clin Exp Nephrol. 2007;11(2):142-6.

8. Salesi M, Karimifar M, Farajzadegan Z, Esalatmanesh K, Khosravi S, Fallahi $P$, et al. The protein-creatinine ratio in spot morning urine samples and 24-h urinary protein excretion in patients with systemic lupus erythematosus. Rheumatol Int. 200;29(5):503-7.

9. Choi IA, Park JK, Lee EY, Song YW, Lee EB. Random spot urine protein to creatinine ratio is a reliable measure of proteinuria in lupus nephritis in Koreans. Clin Exp Rheumatol 2013;31 (4):584-8.

10. Xin G, Wang M, Jiao LL, Xu GB, Wang HY. Protein-to-creatinine ratio in spot urine samples as a predictor of quantitation of proteinuria. Clin Chim Acta. 2004;350(1-2):35-9.

11. Datta S, Pal M. Comparison between different methods of urine collection for estimation of albumin-creatinine ratio in patients with type-2 diabetes mellitus. Advances in Biological Chemistry. 2013;3:403-7.

12. Birmingham DJ, Rovin BH, Shidham G, Bissell M, Nagaraja HN, Hebert LA. Relationship between albuminuria and total proteinuria in systemic lupus erythematosus nephritis: diagnostic and therapeutic implications. Clin J Am Soc Nephrol. Research Support, N.I.H., Extramural. 2008 Jul;3(4):1028-33.

13. Ginsberg JM, Chang BS, Matarese RA, Garella S. Use of single voided urine samples to estimate quantitative proteinuria. N Engl J Med. 1983 Dec 22;309(25):1543-6. 